Article

\title{
Effect of Sphere Properties on Microstructure and Mechanical Performance of Cast Composite Metal Foams
}

\author{
Matias Garcia-Avila and Afsaneh Rabiei * \\ Department of Mechanical and Aerospace Engineering, North Carolina State University 911 Oval \\ Drive, Campus Box 7910, Raleigh, NC 27695, USA; E-Mail: mgarcia2@ncsu.edu \\ * Author to whom correspondence should be addressed; E-Mail: arabiei@ncsu.edu; \\ Tel.: +1-919-513-2674; Fax: +1-919-515-7968.
}

Academic Editor: Hugo F. Lopez

Received: 3 April 2015 / Accepted: 6 May 2015 / Published: 20 May 2015

\begin{abstract}
Aluminum-steel composite metal foams (Al-S CMF) are manufactured using steel hollow spheres, with a variety of sphere carbon content, surface roughness, and wall porosity, embedded in an Aluminum matrix through gravity casting technique. The microstructural and mechanical properties of the material were studied using scanning electron microscopy, energy dispersive spectroscopy, and quasi-static compressive testing. Higher carbon content and surface roughness in the sphere wall were responsible for an increase in formation of intermetallic phases which had a strengthening effect at lower strain levels, increasing the yield strength of the material by a factor of 2, while higher sphere wall porosity resulted in a decrease on the density of the material and improving its cushioning and ductility maintaining its energy absorption capabilities.
\end{abstract}

Keywords: casting; Composite Metal Foam; Al-Fe-Si intermetallic; quasi-static loading; hollow spheres

\section{Introduction}

The use of metal foams for structural applications has been limited due to their non-homogeneous cell-size and cell-shape, which results in their low mechanical properties, premature failure under loading, and their low reliability. Composite metal foam (CMF) has been developed to improve the strength of metal foams by providing an even size, shape, and distribution of porosities. This is achieved 
by packing hollow metal spheres in a random pack arrangement and filling the interstitial spaces between spheres with a metal matrix.

Aluminum matrix CMF with steel hollow spheres has been studied extensively under monotonic compression and fatigue loading [1-8] and has shown mechanical properties unmatched with any other metal foam. As previously reported [3,4,7,8] aluminum-steel (Al-S) CMF contains hard and brittle intermetallic from the Al-Fe-Si ternary system dispersed through the matrix of the material. The formation of intermetallics in the Al-Fe-Si system is a well-studied phenomena [9-15] and is due to the reciprocal diffusion of $\mathrm{Fe}$ and other alloying elements, like $\mathrm{Cr}$ and $\mathrm{Ni}$, from the sphere wall into the Al-Si matrix, at the same time of diffusion of $\mathrm{Al}$ and $\mathrm{Si}$ from the matrix towards the sphere wall. Intermetallic formation in Al-S CMF influences the mechanical properties of the material and for that reason it has been widely studied [1-8]. In this study, the microstructure of Al-S CMF manufactured using spheres with different properties is investigated using SEM images along with EDS analysis. This study will provide an understanding of the effects of sphere wall carbon content, surface roughness, and wall porosity on the formation of these Al-Fe-Si intermetallics and their effect on the material microstructure and mechanical properties.

\section{Materials, Processing, and Experimental Procedure}

\subsection{Materials and Processing}

Aluminum-steel composite metal foam was processed using steel hollow spheres and Aluminum A356 (Al-7\%Si alloy) matrix. Aluminum alloy 356 with 7\% silicon (supplied by Trialco, Inc., Chicago Heights, IL, USA) was chosen as the solid matrix material due to its low density, high strength, ease of casting, and reduced shrinkage during solidification. The steel hollow spheres were produced by Fraunhofer and Hollomet GmbH in Dresden Germany [16,17]. The selection of Al matrix with distinctly lower melting points for casting around steel hollow spheres was to keep the spheres from melting during casting. Two types of hollow spheres were used, with similar outer diameters of about 3.7 and $4.0 \mathrm{~mm}$, and $196 \mu \mathrm{m}$ and $200 \mu \mathrm{m}$ sphere wall thicknesses, respectively. This gives a diameter/wall thickness ratio around 0.2 for both types of spheres, creating a comparable amount of steel content in both composite foams. The two types of spheres had different chemical composition, sphere wall porosity, and surface roughness. The chemical composition of the Aluminum matrix (A356) and both sets of steel spheres are shown in Table 1.

Table 1. Composition (wt $\%$ ) of hollow spheres and aluminum used in manufacturing aluminum-steel composite metal foams (Al-S CMF).

\begin{tabular}{ccccccccccccc}
\hline Component & $\mathbf{F e}$ & $\mathbf{C}$ & $\mathbf{M n}$ & $\mathbf{S i}$ & $\mathbf{C r}$ & $\mathbf{N i}$ & $\mathbf{M o}$ & $\mathbf{A l}$ & $\mathbf{M g}$ & $\mathbf{C u}$ & $\mathbf{T i}$ & $\mathbf{Z n}$ \\
\hline $\begin{array}{c}3.7 \mathrm{~mm} \\
\text { Sphere }\end{array}$ & Balance & 0.03 & 0.20 & 0.90 & 17.00 & 13.00 & 2.20 & 0 & 0 & 0 & 0 & 0 \\
$\begin{array}{l}4.0 \mathrm{~mm} \\
\begin{array}{c}\text { Sphere } \\
\text { Al Matrix }\end{array}\end{array}$ & Balance & 0.64 & 0.11 & 0.73 & 16.91 & 12.35 & 2.20 & 0 & 0 & 0 & 0 & 0 \\
\hline
\end{tabular}


The spheres were placed in a steel permanent casting mold $(83 \mathrm{~mm} \times 57 \mathrm{~mm} \times 104 \mathrm{~mm})$, held at the top with a stainless steel mesh, vibrated to pack in a maximum dense arrangement [3-5] (which is about $59 \%$ of the whole volume) and are pre-heated to $700{ }^{\circ} \mathrm{C}$ in a high temperature furnace along with the aluminum inside a graphite crucible. The furnace used for heating up the spheres, mold and aluminum is a high temperature furnace from CM furnaces 3300 series (Bloomfield, NJ, USA) with molydisilicide heating elements capable of reaching $1700{ }^{\circ} \mathrm{C}$. More details on the processing of composite metal foam via casting are presented elsewhere [1-8].

\subsection{Sample Preparation}

Thin slices of Al-S CMF samples were used to investigate the microstructure using digital, optical, and scanning electron microscopy (SEM) imaging, while rectangular cuboids of foam samples were used for mechanical testing. Samples were cut using a Buehler Isomet linear precision saw (Cleveland, $\mathrm{OH}$, USA) equipped with a wafering blade at a constant blade speed of $2500 \mathrm{rpm}$ and a feed rate of $1.2 \mathrm{~mm}$ per minute. To avoid edge effects, the mechanical test samples were cut to a size of $24 \mathrm{~mm} \times 24 \times \mathrm{mm} 42 \mathrm{~mm}$, having at least 6 cells in each direction and keeping a height-to-width ratio of 1.75. The surfaces of the samples used for microstructural observation were ground using progressive grinding paper from 180 to 1500 grit, followed by polishing using a $3 \mu \mathrm{m}$ diamond slurry, and a progression of $1,0.1$, and 0.05 alumina paste. The samples were washed and ultrasonically cleaned in water/acetone between each stage of grinding and polishing to prevent any cross contamination. Some polished samples were chemically etched in glyceregia (30 mL glycerin, $25 \mathrm{~mL} \mathrm{HCl}$, and $10 \mathrm{~mL} \mathrm{HNO}_{3}$ ) to expose grain boundaries and carbide precipitates in the sphere walls.

\subsection{Microstructural Characterization}

Digital images of the sphere surface and the foam cross section were taken to observe the surface roughness of the spheres and the foam structure after processing. Surface roughness was measured experimentally for both types of spheres using a surface profilometer Taylor Hobson Form Talysurf Series 2 (Taylor Hobson, Inc., Rolling Meadows, IL, USA) with a stylus tip of $6 \mu \mathrm{m}$ in diameter. Each sphere was placed on a sample holder before the stylus tip was brought into contact with the sphere surface and scanned through a measuring length (L). The measurements were collected electronically and the surface roughness was computed using the equation:

$$
\text { Roughness }=\frac{1}{L} \int_{0}^{l}|z(x)| d x
$$

where $z$ is the vertical distance from the mean line at position $x$. A measuring length of $2 \mathrm{~mm}$ is used for both sphere types. Two different spheres were measured from each group, and each sphere was measured twice. The average of measurements are calculated and reported here.

SEM images were obtained using a Hitachi S-3200N Scanning Electron Microscope equipped with Energy Dispersive X-ray Spectroscopy (EDS) system, to identify various phases and precipitates formed in the microstructure of the foam. 


\subsection{Density Calculation}

The packing density of hollow spheres in CMF is previously reported as 59.4\% [1]. In this study, the porosity content in the sphere wall was measured using SEM images and open source imaging software Image J v.1.43u [18] and used to determine the density of the foam. The calculated and experimentally measured densities for various CMF samples are compared and correlated to their mechanical properties.

\subsection{Mechanical Testing}

Compression testing was performed on Al-S CMF samples using an MTS servo-hydraulic testing machine with $890 \mathrm{kN}$ compression force capability, located at Constructed Facilities Lab at North Carolina State University. Tests were performed using crosshead displacement control at $1.25 \mathrm{~mm} / \mathrm{min}$ rate. Sample deformation was monitored using a linear variable differential transducer (LVDT). A thin layer of light grease was used to lubricate the contact surfaces between testing machine and CMF samples to avoid friction and minimize barreling effects. In the absence of any international standard for compression testing of metal foams, this is a common procedure [19] that is followed by the majority of scientists in the metal foam community.

\section{Results}

\subsection{Structural Properties}

Digital images of the cross sections of Al-S CMF samples made with the two sets of spheres and a sample of the corresponding spheres prior to be embedded in the matrix are shown in Figure 1A-C. As can be seen in Figure 1A,B, the structure of Al-S CMF for both spheres exhibits an even distribution of porosities throughout the entire sample. The liquid cast aluminum filled the spaces between the spheres successfully joining the spheres together. SEM images of the microstructure of Al-S CMF made with both types of spheres showing the interface of matrix and spheres are presented in Figure 2A,B.

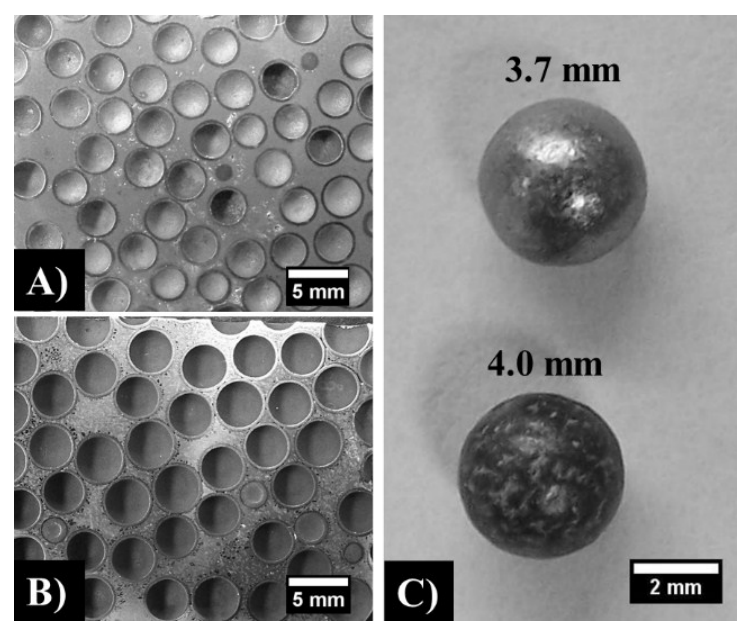

Figure 1. Digital images of the cross section of Al-S CMF samples processed using (A) $3.7 \mathrm{~mm}$ spheres and (B) $4.0 \mathrm{~mm}$ spheres, and (C) 3.7 and $4.0 \mathrm{~mm}$ diameter hollow spheres prior to embedding into the matrix of Al-S CMF showing the difference in their surface roughness detail. 

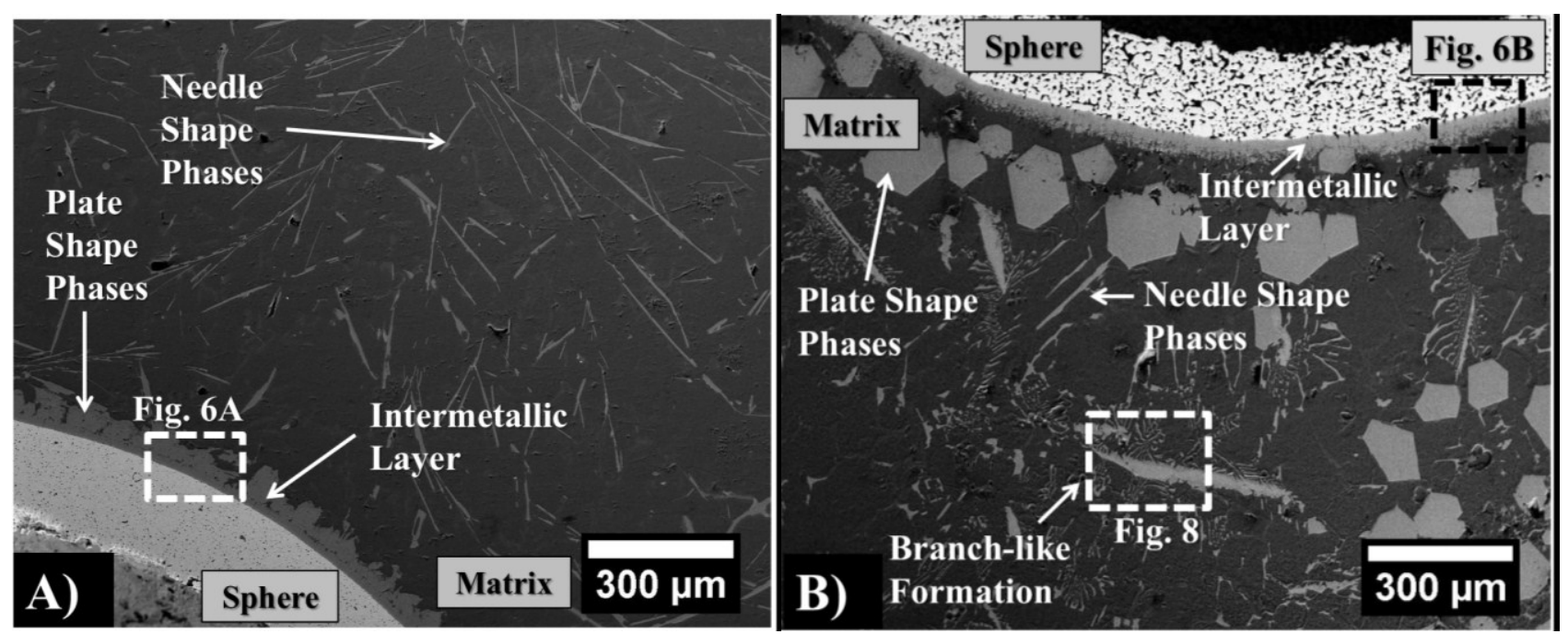

Figure 2. Backscattered SEM images of the microstructure showing intermetallic formations in Al-S CMF samples made with (A) $3.7 \mathrm{~mm}$ and (B) $4.0 \mathrm{~mm}$ spheres.

As shown, the $3.7 \mathrm{~mm}$ spheres have much lower porosity content in the sphere wall compared to the $4.0 \mathrm{~mm}$ spheres. For both samples an intermetallic layer is formed at the interface between the sphere wall and the Al-Si matrix. Further outside the sphere wall and next to the intermetallic layer, plate-shaped intermetallic phases are formed in both samples. Some acicular needle-shaped phases are dispersed within the matrix. These needle-shaped intermetallic phases are almost exclusively occupied the matrix of CMF samples made with $3.7 \mathrm{~mm}$ spheres, but they are less predominant in the $4.0 \mathrm{~mm}$ sphere CMF. Figure 2B shows eutectoid intermetallic formations with branch-like structure dispersed throughout the matrix of CMF samples made with $4 \mathrm{~mm}$ spheres.

Figure 1C along with the results of spheres surface roughness measurements (presented in Table 2), show that $4.0 \mathrm{~mm}$ spheres have $25 \%$ higher surface roughness than the $3.7 \mathrm{~mm}$ spheres. Figure $3 \mathrm{~A}$ shows the formation of a ring of micro-porosities in the matrix and around the sphere walls, right outside the intermetallic layer, which is more prominent in $4.0 \mathrm{~mm}$ sphere Al-S CMF with higher sphere surface roughness. In some cases, these porosities combined to form larger porosities inside the matrix as solidification takes place (Figure 3B).

Table 2. Surface roughness measurements for 3.7 and $4.0 \mathrm{~mm}$ diameter hollow spheres.

\begin{tabular}{cc}
\hline Sphere Diameter $(\mathbf{m m})$ & Roughness $(\boldsymbol{\mu m})$ \\
\hline \multirow{3}{*}{3.7} & 3.897 \\
& 2.944 \\
& 8.418 \\
Average & 2.971 \\
\hline & 4.558 \\
\hline \multirow{2}{*}{4.0} & 6.561 \\
& 5.831 \\
Average & 5.144 \\
\hline
\end{tabular}




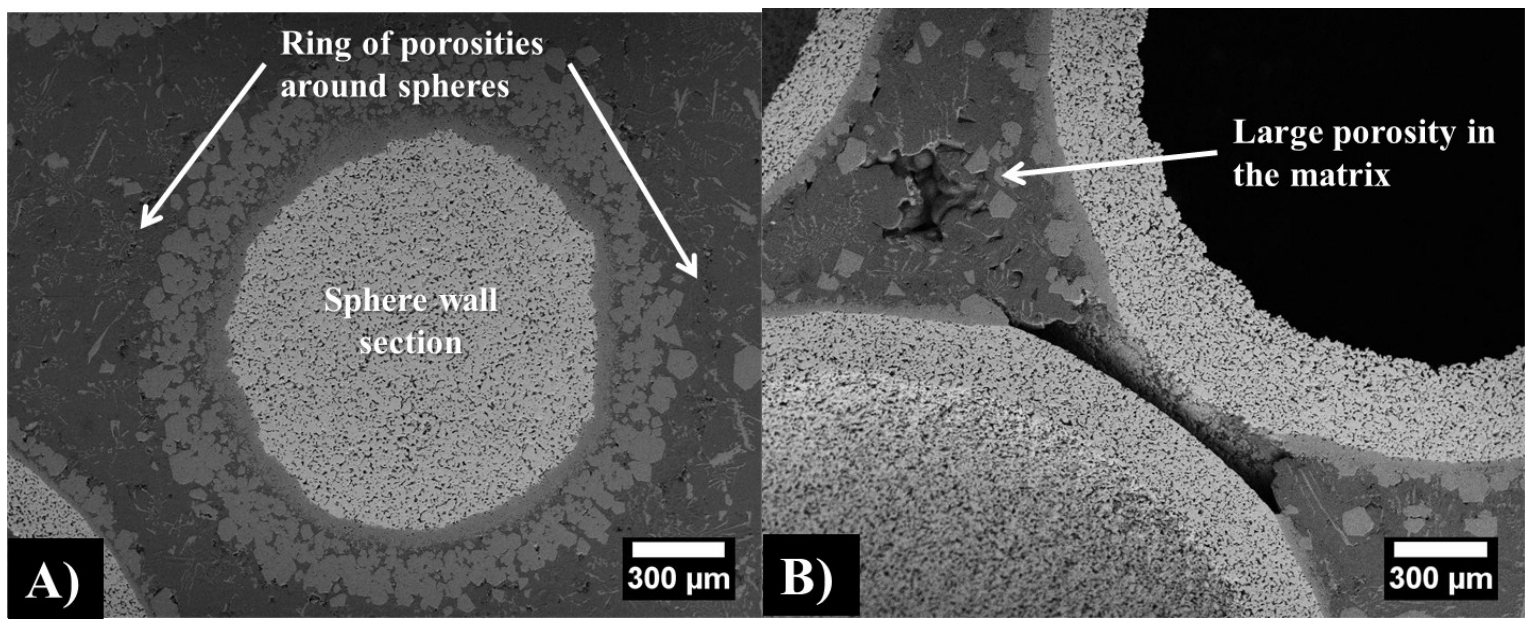

Figure 3. Backscattered SEM image of $4.0 \mathrm{~mm}$ Al-S CMF microstructure showing (A) a ring of micro-porosities around a sphere due to air trapped at the surface roughness of the sphere and (B) large porosity in matrix due to coalescence of micro-porosities.

As seen in Figure 4A, the liquid aluminum has not completely filled the spaces between some of the spheres. This can be due to the surface tension of the aluminum melt. This type of porosity in Al-Steel CMF was previously reported to account for less than $1 \%$ of the total density of the foam [1]. In rare cases in the CMF samples made with $4.0 \mathrm{~mm}$ spheres, the sphere and the matrix are not in contact with each other and show an air pocket at the interface between the two, as seen in Figure 4B.
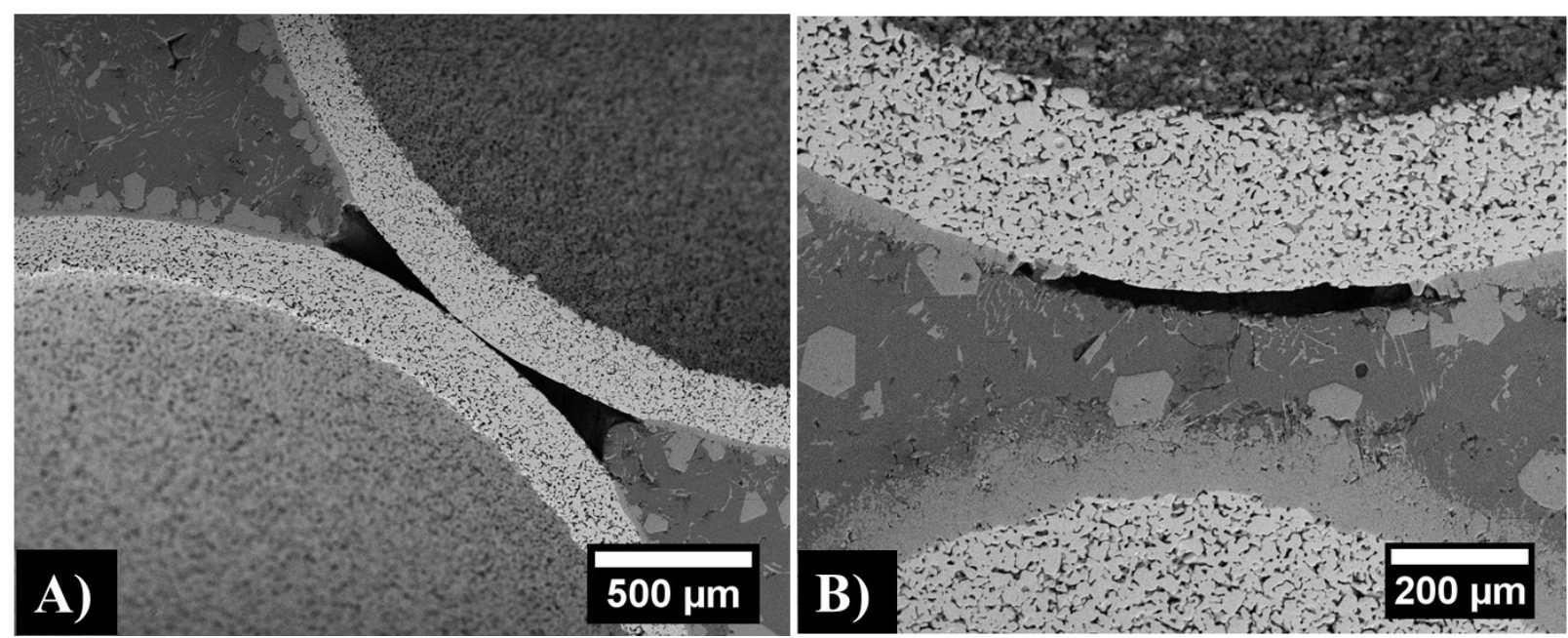

Figure 4. Backscattered SEM microstructure images of Al-S CMF made with $4.0 \mathrm{~mm}$ spheres showing (A) unfilled spaces between spheres due to surface tension of liquid matrix and (B) unfilled spaces at the matrix-sphere interface due to sphere surface roughness.

SEM images in Figure 5A,B offer a comparison of the sphere wall microstructure for both samples made with two different types of spheres. Table 3 shows the calculated sphere wall porosity and wall thickness using previously reported techniques [20]. Results show 5\% and 14\% average wall porosity for the 3.7 and $4.0 \mathrm{~mm}$ spheres, respectively, with 200 and $196 \mu \mathrm{m}$ average wall thickness.

The density of the CMF material is estimated using a theoretical technique previously developed [1] and the results are compared with the measured density in Table 3. It can be seen that the average density 
of CMF samples made of $3.7 \mathrm{~mm}$ spheres is $11 \%-16 \%$ higher than that made of $4.0 \mathrm{~mm}$ spheres. This different is predominantly resulted from the almost $10 \%$ difference in their sphere wall porosity content as well as some additional porosities at the interface of the spheres and matrix due to the air trapping on spheres' surface features.

Table 3. Al-S CMF parameters including measured and predicted density.

\begin{tabular}{ccccc}
\hline $\begin{array}{c}\text { Sphere Diameter } \\
(\mathbf{m m})\end{array}$ & $\begin{array}{c}\text { Sphere Wall } \\
\text { Thickness }(\boldsymbol{\mu m})\end{array}$ & $\begin{array}{c}\text { Sphere Wall } \\
\text { Porosity }(\mathbf{\%})\end{array}$ & $\begin{array}{c}\text { Measured Density } \\
\left(\mathbf{g} / \mathbf{c m}^{\mathbf{3}}\right)\end{array}$ & $\begin{array}{c}\text { Estimated Density } \\
\left(\mathbf{g} / \mathbf{c m}^{\mathbf{3}}\right)\end{array}$ \\
\hline 3.7 & 200 & 5.0 & 2.5 & 2.4 \\
4.0 & 196 & 14.0 & 2.0 & 2.1 \\
\hline
\end{tabular}

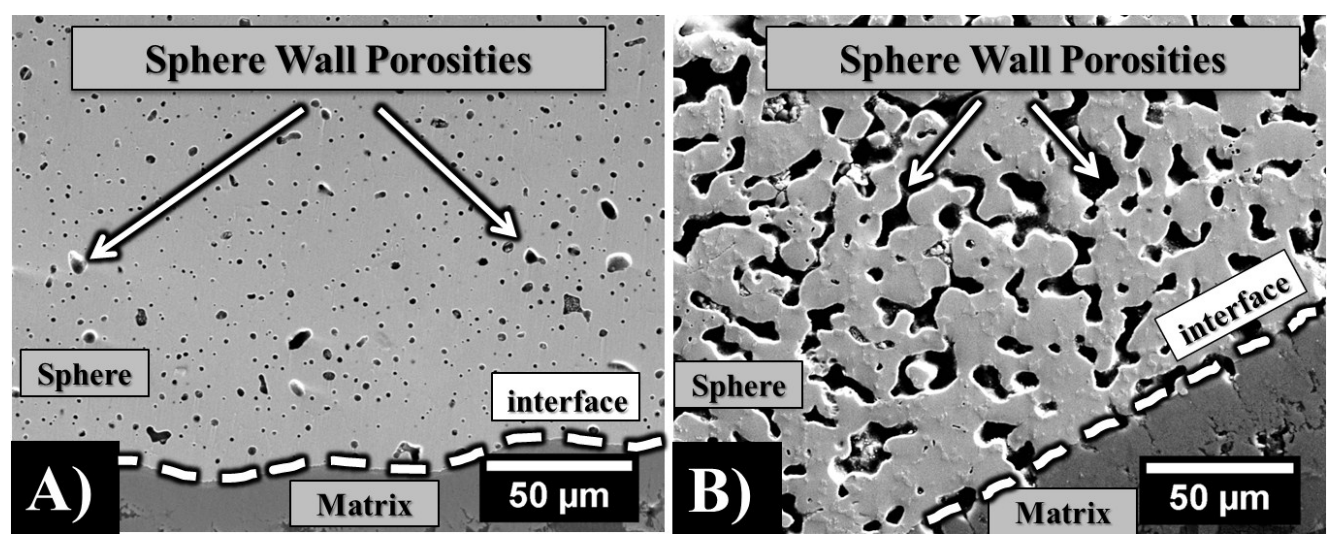

Figure 5. Secondary electron SEM images of the sphere wall microstructure for Al-S CMF made with (A) $3.7 \mathrm{~mm}$ and (B) $4.0 \mathrm{~mm}$ sphere.

EDS analysis was performed throughout the microstructure in order to understand the differences in composition between the intermetallic phases and the results are reported in Table 4.

Table 4. EDS results showing the composition of intermetallic phases and Al matrix (in atomic \%) for both Al-S CMFs made with 3.7 and $4.0 \mathrm{~mm}$ sphere.

\begin{tabular}{ccccccccc}
\hline 3.7 mm & $\mathbf{F e}$ & $\mathbf{C r}$ & $\mathbf{N i}$ & $\mathbf{( F e C r N i})$ & $\mathbf{M n}$ & $\mathbf{M o}$ & $\mathbf{A l}$ & $\mathbf{S i}$ \\
\hline Intermetallic Layer & 16.40 & 4.10 & 0.00 & 20.50 & 0.40 & 0.00 & 72.00 & 7.90 \\
Plate Shape & 11.91 & 2.11 & 0.03 & 14.05 & 1.11 & 0.02 & 75.96 & 8.87 \\
Needle Shape & 12.57 & 0.02 & 0.06 & 12.65 & 0.22 & 0.00 & 70.93 & 16.21 \\
Si Precipitate & 0.00 & 0.00 & 0.04 & 0.04 & 0.02 & 0.00 & 2.94 & 97.00 \\
Al Matrix & 0.02 & 0.02 & 0.03 & 0.07 & 0.00 & 0.00 & 98.35 & 1.58 \\
\hline 4.0 mm & $\mathbf{F e}$ & $\mathbf{C r}$ & $\mathbf{N i}$ & $\mathbf{( F e C r N i )}$ & $\mathbf{M n}$ & $\mathbf{M o}$ & $\mathrm{Al}$ & $\mathrm{Si}$ \\
\hline Intermetallic Layer (Light) & 19.27 & 3.56 & 1.42 & 24.25 & 0.07 & 0.17 & 71.32 & 4.19 \\
Intermetallic Layer (Dark) & 8.70 & 3.66 & 0.41 & 12.77 & 0.08 & 0.14 & 80.00 & 7.01 \\
Plate Shape & 13.12 & 3.66 & 0.47 & 17.25 & 0.07 & 0.00 & 75.37 & 5.91 \\
Needle Shape & 5.76 & 0.01 & 3.14 & 8.91 & 0.00 & 0.00 & 85.78 & 3.33 \\
Branch-like Phase (inner light) & 17.00 & 2.47 & 1.43 & 20.90 & 0.80 & 0.00 & 76.67 & 2.38 \\
Branch-like Phase (outer dark) & 14.81 & 1.58 & 0.58 & 16.97 & 0.06 & 0.00 & 75.58 & 7.38 \\
Si Precipitate (Not found) & - & - & - & - & - & - & - & - \\
Al Matrix & 0.08 & 0.01 & 0.04 & 0.13 & 0.02 & 0.00 & 98.45 & 1.40 \\
\hline
\end{tabular}


Intermetallic formation in Al-Fe-Si has been studied extensively and is well documented [9,10,21-24]. As a note, all intermetallic phases found in Al-S CMF include some traces of alloying elements $\mathrm{Cr}$ and $\mathrm{Ni}$, which have diffused from the sphere wall into the matrix, occupying the sites of Fe atoms in the Al-Fe-Si intermetallic phases $[11,12]$. For this reason, and in order to identify the phases in the Al-Fe-Si ternary system, the atomic concentrations of $\mathrm{Fe}, \mathrm{Cr}$, and $\mathrm{Ni}$ in the intermetallic phases are combined and shown as (FeCrNi) in Table 4.

Figure 6A-D shows high magnification SEM images of etched CMF samples made with the two different hollow spheres. As can be seen, $\mathrm{Cr}$ carbides are precipitated along the grain boundaries of steel spheres in both samples, but in the CMF made with $4.0 \mathrm{~mm}$ sphere, $\mathrm{Cr}$ carbide precipitations are more visible both along the grain boundaries and within the sphere wall grains.

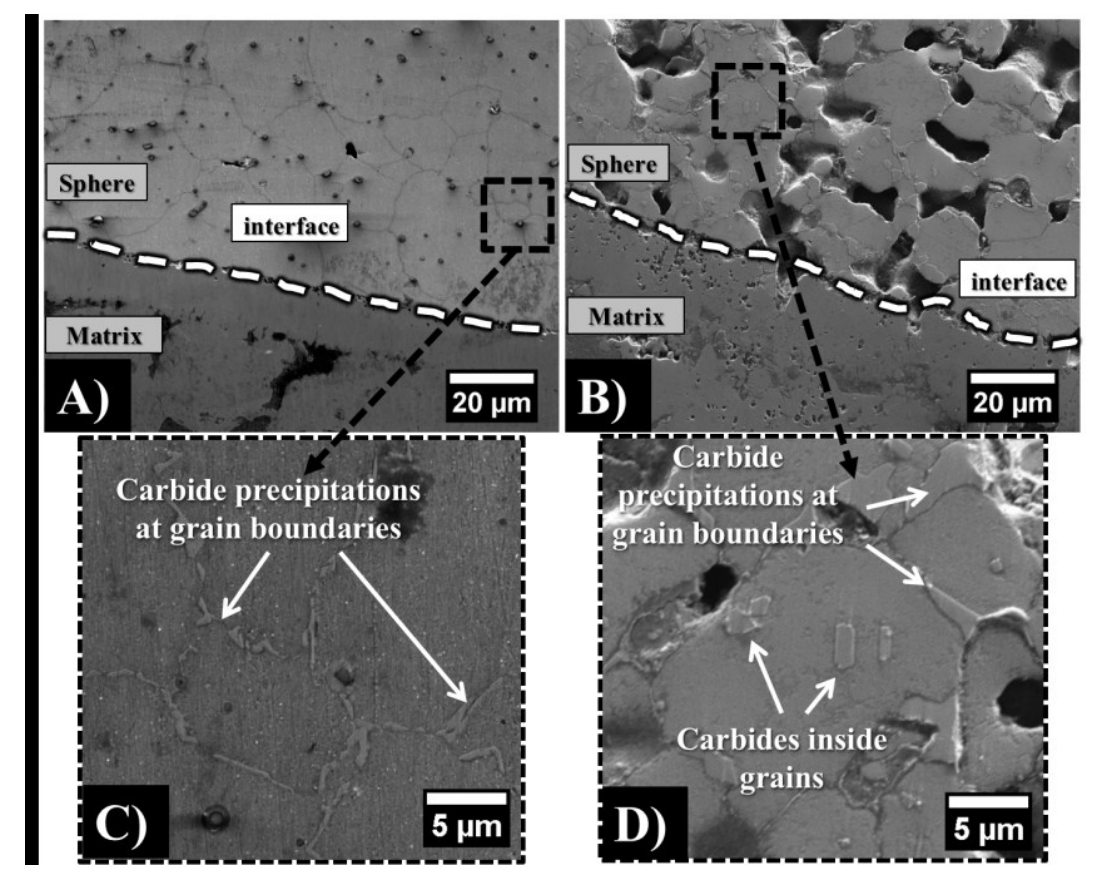

Figure 6. Secondary-electron SEM images of etched samples at higher magnification for Al-S CMF made with (A) $3.7 \mathrm{~mm}$ sphere; (B) $4.0 \mathrm{~mm}$ sphere, and detail of sphere wall microstructure for (C) $3.7 \mathrm{~mm}$ and (D) $4.0 \mathrm{~mm}$ sphere.

During processing of Al-S CMF, inter-diffusion of Al and Si from the matrix into the sphere wall, along with $\mathrm{Fe}$ and other alloying elements from the sphere wall towards the matrix, form an intermetallic layer, shown as a grey layer on the outer surface of the spheres of both samples (Figure 7A,B).

The average thickness of this intermetallic layer is about $17 \mu \mathrm{m}$ for both samples. The structure and composition of the intermetallic layer outside the spheres differs in each sample. While the CMF samples made with $3.7 \mathrm{~mm}$ sphere show a uniform mono-layer intermetallic, the $4.0 \mathrm{~mm}$ sphere CMF samples have a two- phase intermetallic layer as shown with a lighter and darker grey phases in Figure 7. The inter-diffusion continues during solidification of Al-Si matrix and ends up with the formation of plate-shaped intermetallic phases, adjacent to the intermetallic layer, with different chemical composition than that of the intermetallic layer (Figure 2A,B). As shown in Table 4, CMF samples made with $4.0 \mathrm{~mm}$ sphere have higher concentration of $\mathrm{FeCrNi}$ with lower concentration of $\mathrm{Si}$ in their intermetallic 
phase, compared to the CMFs made with $3.7 \mathrm{~mm}$ spheres. As diffusion takes place during solidification, these plate-shaped intermetallics grow, detach from the intermetallic layer, and move into the Al matrix.

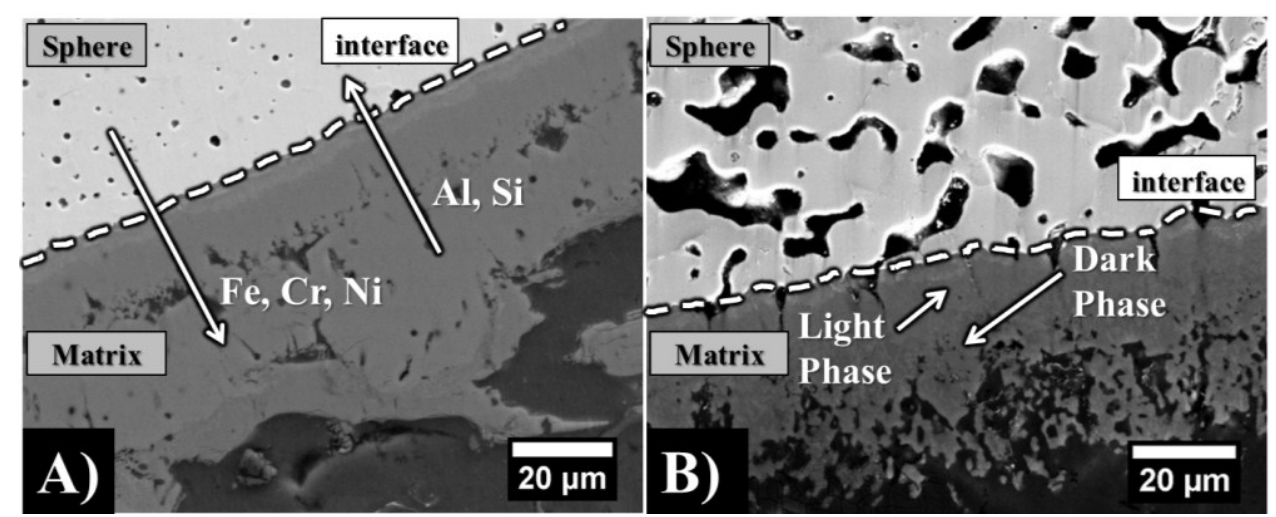

Figure 7. Backscattered SEM images of the microstructure at the sphere-matrix interface showing the intermetallic layer for Al-S CMF samples made with (A) $3.7 \mathrm{~mm}$ and (B) $4.0 \mathrm{~mm}$ sphere.

Further investigation on the microstructure of the two sets of samples shows eutectoid branch-like intermetallic formations in the $4.0 \mathrm{~mm}$ sphere CMF samples, with a two-phase structure formed by a lighter inner phase surrounded by a darker outer phase (Figure 8). EDS showed that the inner lighter phase contains a high concentration of $\mathrm{FeCrNi}$ and $\mathrm{Mn}$, and low amounts of Si, while the outer darker phase contains less $\mathrm{FeCrNi}$ and $\mathrm{Mn}$ with higher amounts of $\mathrm{Si}$. These branch-like intermetallic formations are not found in the $3.7 \mathrm{~mm}$ sphere CMF samples.

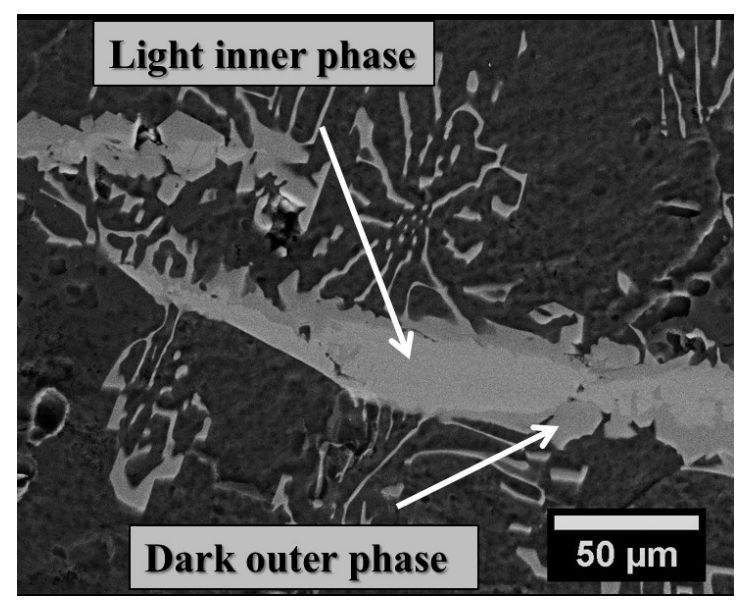

Figure 8. Backscattered SEM image of branch-like formations observed in the $4.0 \mathrm{~mm}$ sphere CMF samples.

Figure 2A,B shows the precipitation of needle-shape phases, which are predominant in the matrix of the CMF samples made with $3.7 \mathrm{~mm}$ spheres (Figure 2A) and are rare in the $4.0 \mathrm{~mm}$ sphere CMF samples (Figure 2B). As shown in Table 4, these needle-shape intermetallic phases are rich in Si.

It appears that the higher concentration of carbon content in spheres with $4 \mathrm{~mm}$ diameter along with their larger surface roughness and contact area with the matrix facilitated the inter-diffusion of alloying elements and promoted the formation of ternary intermetallic phases of FeAlSi. As such, the majority of 
the Si from the aluminum matrix is consumed by those ternary intermetallic phases of AlFeSi leaving less Si for precipitation as needle-shape phases. Samples made with lower sphere roughness and lower carbon content had less intermetallic formation and the Si was deposited individually as needle-shape phases (CMFs made with $3.7 \mathrm{~mm}$ spheres). Figure 9 shows single phase Si precipitations dispersed through the matrix of a CMF made with $3.7 \mathrm{~mm}$ sphere.

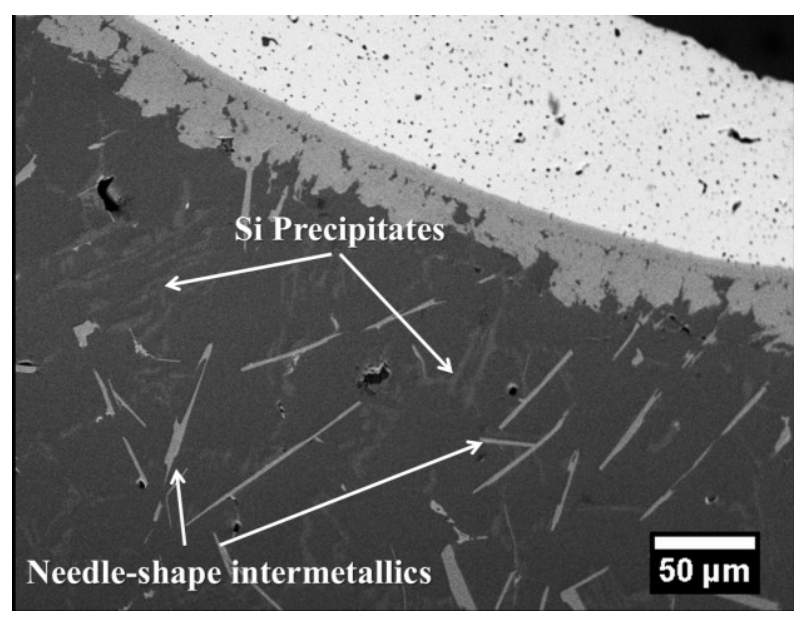

Figure 9. Backscattered SEM image of needle-shape intermetallics and Si precipitates in Al-S CMF sample made with $3.7 \mathrm{~mm}$.

\subsection{Mechanical Properties}

The monotonic compression tests results for CMFs made with both types of spheres are shown in Figure 10A,B, with Figure 10A showing the engineering stress vs. strain data, and Figure 10B showing the specific engineering stress $v s$. Strain. Specific stress is the stress divided by the average density of the foam and is used in order to eliminate the effect of density. The $0.2 \%$ strain offset yield strength along with the energy absorption and specific energy absorption at 50\% strain are calculated and shown in Table 5.

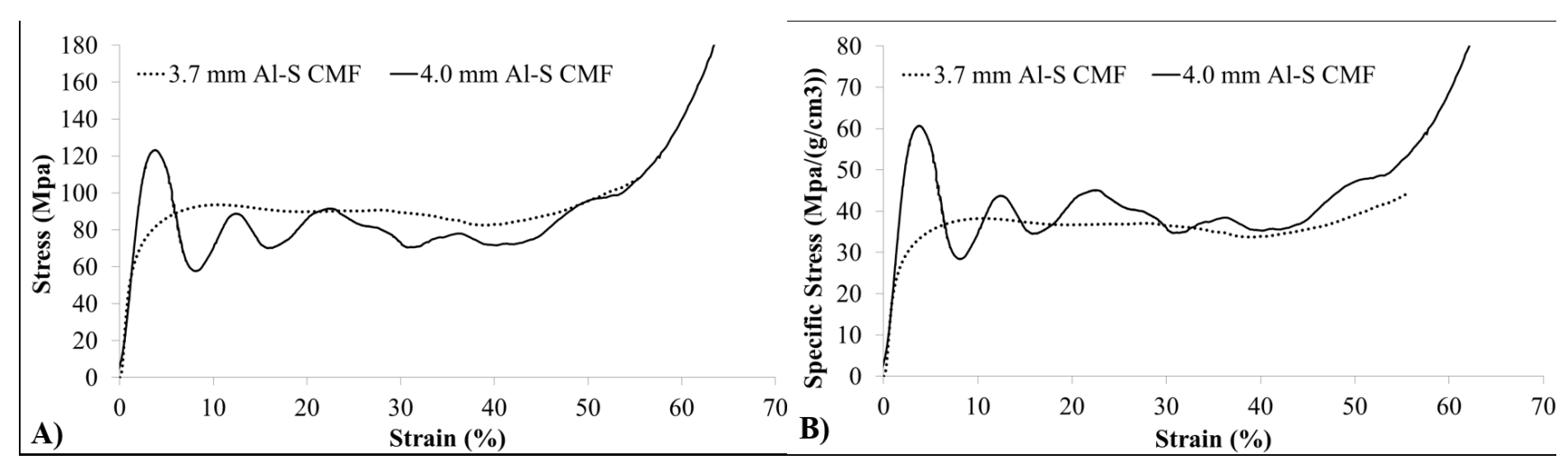

Figure 10. (A) Engineering stress vs. strain and (B) Specific engineering stress (stress/density) vs. strain plots for quasi-static compression tests on Al-S CMF manufactured using $3.7 \mathrm{~mm}$ and $4.0 \mathrm{~mm}$ spheres. 
Table 5. Yield strength and energy absorption in Al-S CMF samples made with for $3.7 \mathrm{~mm}$ and $4.0 \mathrm{~mm}$.

\begin{tabular}{ccccc}
\hline CMF & $\begin{array}{c}\text { Density } \\
\left(\mathbf{g} / \mathbf{c m}^{\mathbf{3}}\right)\end{array}$ & $\begin{array}{c}\text { Yield Strength } \\
(\mathbf{M P a})\end{array}$ & $\begin{array}{c}\text { Energy abs. at 50\% strain } \\
\left(\mathbf{M J} / \mathbf{m}^{3}\right)\end{array}$ & $\begin{array}{c}\text { Spec. Energy abs. at } \mathbf{5 0 \%} \\
\text { strain }(\mathbf{J} / \mathbf{g})\end{array}$ \\
\hline $3.7 \mathrm{~mm}$ & 2.5 & 52 & 43.31 & 17.32 \\
$4.0 \mathrm{~mm}$ & 2.0 & 110 & 40.02 & 20.01 \\
\hline
\end{tabular}

It can be seen that the CMF samples made with $4.0 \mathrm{~mm}$ sphere (higher carbon content and higher surface roughness) show a $110 \%$ improvement in their yield strength compared with the CMF samples made with $3.7 \mathrm{~mm}$ sphere. The energy absorption at 50\% strain are almost the same for both samples, while a $20 \%$ improvement in specific energy absorption is observed in the CMF samples made with $4.0 \mathrm{~mm}$ spheres due to their higher carbon content and brittle intermetallic phases.

\section{Discussion}

\subsection{Effect of Sphere Surface Roughness and Wall Porosity}

The ring of micro porosities (shown in Figure 3A) caused by the surface roughness of the spheres and air trapping on those surface features when casting takes place. Such trapped air cannot escape through the highly viscose liquid $\mathrm{Al}$ and can only be slightly pushed away from sphere wall into the matrix during solidification, forming the ring of porosities around sphere. These porosities could marginally compromise the bonding between the spheres and the matrix, lowering the strength of the material after the yield point explaining the drop in the stress-strain curve. A rare feature including very large imperfection at the surface of the spheres can cause larger pockets of air trapped in isolated areas at the sphere-matrix interface, as shown in Figure 4B. The absence of intermetallic layer formation in such area suggests that the surface imperfections prevented the liquid aluminum to come in touch with spheres. Although such features are rare, these voids can potentially lower the strength of the foam mainly after yield point when the matrix starts to undergo plastic deformation. As the percentage of such porosities is small, their effect on the mechanical performance of CMFs is very minimal.

In most spheres, however, the surface roughness is not that large to prevent the liquid aluminum to come in touch with spheres. In such cases the surface roughness can provide larger contact area between the aluminum matrix and the steel spheres, resulting in more elemental diffusion between spheres and the matrix and the formation of higher amount of intermetallic phases. These intermetallic phases will have a hardening effect on the material and improve its performance under loading, particularly boosting the yield point of the material.

The larger amount of porosities in the sphere wall of CMF processed with $4.0 \mathrm{~mm}$ spheres caused a lower density of the material and further improved its cushioning property, which helped attenuating the brittle behavior of the material resulted from its higher intermetallic content. As the result, the Al-S CMF made with $4.0 \mathrm{~mm}$ spheres could sustain a higher plateau strength, maintaining a high energy absorption capability, and improving the material's specific energy absorption by almost $20 \%$. 


\subsection{Effect of Sphere Wall Carbon Content and Chemical Composition}

As shown in Table 1, the composition of Al-Si matrix material used in processing of both sets of CMF samples was identical. However, the chemical composition of the spheres was different, with the $3.7 \mathrm{~mm}$ spheres have lower carbon content compared to the $4.0 \mathrm{~mm}$ spheres. Figure 6B,D showed large amounts of carbide precipitates at the grain boundaries and inside the grains of the sphere wall of CMF made with $4.0 \mathrm{~mm}$ spheres. These carbides are mostly $\mathrm{M}_{23} \mathrm{C}_{6}$, which is the main carbide precipitation in stainless steel [25], and are formed due to the high carbon content inside the sphere wall and the high temperature exposure of the spheres during casting of CMF. The large amount of chromium carbide precipitation in the $4.0 \mathrm{~mm}$ spheres reduces the $\mathrm{Cr}$ content within the sphere grains, and as a result, increases the ratio of $\mathrm{Fe}$ and $\mathrm{Ni}$ inside the steel sphere wall grains, as shown in the EDS results in Table 4. In contrast, the low amount of $\mathrm{C}$ inside the sphere wall of the $3.7 \mathrm{~mm}$ sphere does not strongly promote $\mathrm{Cr}$ carbide formation at the grain boundaries, thus the ratio of $\mathrm{Cr}$ in the sphere grains is higher and that of $\mathrm{Fe}$ and $\mathrm{Ni}$ subsequently are lower. Since $\mathrm{Fe}$ is one of the main elements controlling the formation of the Al-Fe-Si intermetallics, the higher percentage of $\mathrm{Fe}$ result in a higher amount of intermetallic phases formation in the Al-S CMF samples made with $4.0 \mathrm{~mm}$ spheres. In other words, higher carbon content in the sphere wall will lead to lower $\mathrm{Cr}$ available and thus higher proportions of $\mathrm{Fe}$ in the sphere wall grains, which will promote higher diffusion of $\mathrm{Fe}$ and alloying elements, like $\mathrm{Ni}$ and $\mathrm{Mn}$, into the matrix and promote intermetallic formation in the material. This translates into a higher concentration of such elements in the lighter grey intermetallic layer close to the sphere surface, compared to the intermetallic layer of the CMF samples made with $3.7 \mathrm{~mm}$ spheres. The dark gray phases on the outer-most area of the intermetallic layer of these samples contain more Si similar to the intermetallic layer in the CMF samples made with $3.7 \mathrm{~mm}$ sphere.

The CMF sample made with $3.7 \mathrm{~mm}$ sphere showed thin needle shape precipitations dispersed throughout the matrix, as seen in Figure 9, while the samples made with $4 \mathrm{~mm}$ spheres showed eutectoid branch-like intermetallic phase formation resulted from the large amounts of elemental diffusion from sphere wall into the matrix. As seen in Figure 8, branch-like intermetallic phases in the matrix contain large amount of $\mathrm{Si}$ at the outer layer and more concentration of $\mathrm{Mn}$ in the inner layers of branches, creating two distinct shades in the SEM images. This result agrees with other studies in which Mn content controls the diffusion of Si in Al-Fe intermetallic phases [14].

In summary, the higher carbon content in the sphere wall promoted the formation of hard intermetallic phases in the matrix of the CMF samples made with $4.0 \mathrm{~mm}$ sphere and had a hardening effect on the foam boosting up its yield strength by a factor of 2 compared to the CMF samples made with $3.7 \mathrm{~mm}$ spheres. Although the hard and brittle nature of the intermetallic phases causes a drop on the strength of $4.0 \mathrm{~mm}$ sphere CMF after yielding (Figure 10A,B), the higher sphere wall porosity counteracted that effect, balancing the total energy absorption capability of the material between the two sets of samples.

\section{Conclusions}

Al-steel composite metal foam was manufactured using 3.7 and $4.0 \mathrm{~mm}$ diameter hollow steel spheres. Higher carbon content in the sphere wall, along with its higher sphere surface roughness resulted in higher amounts of hard and brittle ternary Al-Fe-Si intermetallic phases dispersed throughout the Al 
matrix, which caused a $110 \%$ improvement on the yield strength of the material. Higher sphere wall porosity, translated into lower density of the material, which provided ductility after yield point, counteracting the increased brittleness of the material, and allowed Al-S CMF to maintain its energy absorption capabilities and increase its specific energy absorption by almost $20 \%$.

\section{Author Contributions}

Afsaneh Rabiei conceived and designed the experiments; Matias Garcia-Avila performed the experiments; Matias Garcia-Avila and Afsaneh Rabiei analyzed the data; Companies mentioned in paper contributed reagents/materials and tools; Matias Garcia-Avila and Afsaneh Rabiei analyzed the results and wrote the paper.

\section{Conflicts of Interest}

The authors declare no conflict of interest.

\section{References}

1. Rabiei, A.; O’Neill, A.T. A study on processing of a composite metal foam via casting. Mater. Sci. Eng. A 2005, 404, 159-164.

2. Rabiei, A.; Vendra, L.; Reese, N.; Young, N.; Neville, B.P. Processing and characterization of a new composite metal foam. Mater. Trans. 2006, 47, 2148-2153.

3. Vendra, L.J.; Rabiei, A. A study on aluminum-steel composite metal foam processed by casting. Mater. Sci. Eng. A 2007, 465, 59-67.

4. Rabiei, A.; Vendra, L.J. A comparison of composite metal foam's properties and other comparable metal foams. Mater. Lett. 2009, 63, 533-536.

5. Vendra, L.; Rabiei, A. Evaluation of modulus of elasticity of composite metal foams by experimental and numerical techniques. Mater. Sci. Eng. A 2010, 527, 1784-1790.

6. Rabiei, A.; Neville, B.; Reese, N.; Vendra, L. New composite metal foams under compressive cyclic loading. Mater. Sci. Forum 2007, 539-543, 1868-1873.

7. Vendra, L.; Neville, B.; Rabiei, A. Fatigue in aluminum-steel and steel-steel composite foams. Mater. Sci. Eng. A 2009, 517, 146-153.

8. Vendra, L.J.; Brown, J.A.; Rabiei, A. Effect of processing parameters on the microstructure and mechanical properties of Al-steel composite foam. Mater. J. Sci. 2011, 46, 4574-4581.

9. Gupta, S.P. Intermetallic compound formation in Fe-Al-Si ternary system: Part I. Mater. Charact. 2002, 49, 269-291.

10. Maitra, T.; Gupta, S.P. Intermetallic compound formation in Fe-Al-Si ternary system: Part II. Mater. Charact. 2002, 49, 293-311.

11. Barbier, F.; Manuelli, D.; Bouché, K. Characterization of aluminide coatings formed on 1.4914 and 316L steels by hot-dipping in molten aluminum. Scr. Mater. 1997, 36, 425-431.

12. Colin, C.; Marchal, Y.; Boland, F.; Delannay, F. Stainless steel fibre reinforced aluminum matrix composites processed by squeeze casting: Relationship between processing conditions and interfacial microstructure. J. Phys. IV 1993, 03, 1749-1752. 
13. Frutos, E.; González-Carrasco, J.L.; Capdevila, C.; Jiménez, J.A.; Houbaert, Y. Development of hard intermetallic coatings on austenitic stainless steel by hot dipping in an Al-Si alloy. Surf. Coat. Technol. 2009, 203, 2916-2920.

14. Warmuzek, M.; Gazda, A.; Anal, J. An analysis of cooling rate influence on the sequence of intermetallic phases precipitation in some commercial aluminum alloys. At. Spectrom. 1999, 14, $535-537$.

15. Wang, Y.; Jones, H.; Evans, P.V. Eutectic solidification characteristics of Bridgman grown Al-3Fe-0.1V alloy. Mater. J. Sci. 1998, 33, 5205-5220.

16. Andersen, O.; Waag, U.; Schneider, L.; Stephani, G.; Kieback, B. Novel metallic hollow sphere structures. Adv. Eng. Mater. 2000, 2, 192-195.

17. Stephani, G.; Kupp, D.; Claar, T.D.; Waag, U. Fabrication of Ti-based components with controlled porosity. Int. Conf. Powder Metall. Part. Mater. 2001, 50-58.

18. Image J. Software. Available online: http://rsbweb.nih.gov/ij (accessed on 18 May 2015).

19. Ashby, M.F.; Evans, A.G.; Fleck, N.A.; Gibson, L.J.; Hutchinson, J.W.; Wadley, H.N.G. Metal Foams, A Design Guide; Butterworth-Heinemann: Woburn, MA, USA, 2000.

20. Rabiei, A.; Garcia-Avila, M. Effect of various parameters on properties of composite steel foams under variety of loading rates. Mater. Sci. Eng. A 2013, 564, 539-547.

21. Viala, M.; Peronnet, M.; Barbeau, F.; Bosselet, F.; Bouix, J. Interface chemistry in aluminium alloy castings reinforced with iron base inserts. Compos. Part A Appl. Sci. Manuf. 2002, 33, 1417-1420.

22. Han, Y.; Ban, C.; Zhang, H.; Nagaumi, H.; Ba, Q.; Cui, J. Investigations on the solidification behavior of Al-Fe-Si alloy in an alternating magnetic field. Mater. Trans. 2006, 47, 2092-2098.

23. Barros, J.; Malengler, B.; van Keer, R.; Houbaert, Y. Modeling silicon and aluminum diffusion in electrical steel. JPEDAV 2005, 26, 417-422.

24. Cheng, W.J.; Wang, C.J. Microstructural evolution of intermetallic layer in hot-dipped aluminide mild steel with silicon addition. Surf. Coat. Technol. 2011, 205, 4726-4731.

25. Durand-Charre, M. Microstructure of Steels and Cast Irons; Springer: New York, NY, USA, 2004.

(C) 2015 by the authors; licensee MDPI, Basel, Switzerland. This article is an open access article distributed under the terms and conditions of the Creative Commons Attribution license (http://creativecommons.org/licenses/by/4.0/). 